\title{
Responsabilidade e carga psíquica na gestão de risco
}

\author{
Maria de Lurdes Costa Domingos ${ }^{\mathrm{I}, 1}$, Leandro de Lima Borges Lins ${ }^{\mathrm{II}, 2}$ \\ ${ }^{\mathrm{I}}$ Universidade Federal do Rio de Janeiro (Rio de Janeiro, RJ, Brasil) \\ ${ }^{\text {II } U n i v e r s i d a d e ~ V e i g a ~ d e ~ A l m e i d a ~(R i o ~ d e ~ J a n e i r o, ~ R J, ~ B r a s i l) ~}$
}

\begin{abstract}
Este trabalho visa analisar a responsabilidade e a carga psíquica na gestão de risco. Observa-se que historicamente risco e responsabilidade estão intrinsecamente associados. Discute-se a emergência e o desenvolvimento da responsabilidade na interação entre a dinâmica psíquica individual e o contexto ambiental. Reflete-se sobre a carga psíquica que a gestão de risco no gerenciamento da excelência exerce sobre o trabalhador. A amostra foi realizada nos setores de petróleo e gás, segurança pública do estado do Rio de Janeiro, investimentos e também na gestão de multidões e grandes eventos. Os dados, coletados em duas entrevistas abertas e oito entrevistas semiestruturadas, foram submetidos à análise de conteúdo. Os resultados indicaram que os gestores de risco de organizações contemporâneas possuem altos níveis de ansiedade mobilizada pela cobrança interna e externa para prevenir desastres em um futuro incerto. Sugere-se o desenvolvimento de mecanismos organizacionais que favoreçam a oxigenação da tensão que mobiliza esse profissional ao enfrentamento dos riscos ameaçadores do viver saudável.
\end{abstract}

Palavras-chave: Gestão de risco, Gestão da excelência, Responsabilidade, Carga psíquica.

Responsibility and psychic charge in risk management

This paper analyzes the issue of responsibility and psychic charge in risk management. It is observed that, historically, risk and responsibility are intrinsically linked. It is discussed the emergence and development of responsibility in the interaction between the individual psychic dynamics and the environmental context. It reflects on the psychic charge that risk management in the excellence management exercises over the worker. The research was taken in the sectors of oil and gas, public security of the State of Rio de Janeiro, investments and also in the management of crowds and major events. The data collected in two open interviews and eight semi-structured interviews underwent the content analysis. Results indicated that risk managers of contemporary organizations have high levels of anxiety mobilized by the charge to prevent internal and external disasters in an uncertain future. It is suggested the development of organizational mechanisms that promote oxygenation of this tension that mobilizes the professional to face the risks threatening the healthy life.

Keywords: Risk management, Excellence management, Responsibility, Psychic charge.

\section{Introdução}

\begin{abstract}
A partir da pesquisa exploratória Representações sociais da gestão de risco: limites sob a ótica do trabalhador, este texto discute questões de responsabilidade e de carga psíquica associadas à gestão de risco. Após identificar altos índices de ansiedade em profissionais que atuam com atividades de risco nas áreas de petróleo e gás, segurança pública, investimentos e na gestão de multidões e grandes eventos, problematiza-se a incidência da responsabilidade e da carga psíquica nessa função. A cobrança externa e, principalmente, a autocobrança sobre a responsabilidade do destino da organização em tempos de flexibilidade é parte intrínseca e constante deste trabalho, bem como se estuda o gestor que tem a capacidade de se preocupar com o outro, responsabilizandose pelo enfrentamento do risco, fato que sem o apoio institucional pode gerar forte carga psíquica e torna-lo vítima de falhas e de adoecimento diante da desgastante tarefa de prevenir desastres em um futuro incerto.
\end{abstract}

A incerteza e o risco são parte da vida e seu enfrentamento é uma demonstração de estar vivo (La Mendola, 2005). No entanto, o acelerado processo de industrialização que a interdependência de mercados proporcionou após a década de 1980 trouxe problemas em grande escala que não

1 Professora doutora do Laboratório de Tecnologia, Gestão de Negócio e Meio Ambiente.

2 Mestrando em Psicossociologia de Comunidades e Ecologia Social. 
amiúde geram graves repercussões para as indústrias, para os trabalhadores e para as populações de seu entorno (Chamon, \& Moraes, 2011). Fatores de risco são interpretados como ameaçadores da sustentabilidade organizacional porque além de afetar seus resultados também podem impedir oportunidades futuras de investimento (Kimura, \& Perera, 2005). Para os trabalhadores, as maiores dificuldades são associadas às mudanças do trabalho. A transferência de processos produtivos de risco (ambiental e/ou para a saúde) de países mais ricos para países mais pobres mudam o perfil da força de trabalho empregada (Mendes, \& Dias, 1991), alteram a compreensão do tempo-espaço e as formas de sociabilidade com impactos na saúde de um trabalhador responsabilizado pelas mudanças em curso (Moulin, \& Moraes, 2010). Do lado social, questões de segurança e de risco em larga escala são mobilizadas por desastres naturais com efeitos tão drásticos quanto os de acidentes que atingiram populações no entorno industrial. Em janeiro de 2011, chuvas fortíssimas mataram cerca de mil pessoas em Teresópolis e Nova Friburgo no Brasil. Em março daquele ano, um tsunami avassalou o Japão registrando mais de 28 mil mortos. Além das vítimas, os eventos atingiram fortemente a produção e a economia desses territórios. A mesma dramaticidade acompanhou na década de 1980 o vazamento de 40 toneladas de gases tóxicos da Union Carbide em Bophal, na Índia; o derramamento de 700 mil litros de gasolina no mangue da favela incendiada de Vila Socó em Cubatão no Brasil; e o acidente nuclear de Chernobyl, na Ucrânia. O aspecto mais drástico dessa descrição é a compreensão de que se o risco e a incerteza são fabricados pela sociedade moderna (Giddens, 2007), essas situações não estão ultrapassadas. Sem data e sem hora marcada voltarão a acontecer. Quando se trata de riscos, ordem-certeza-desordem-incerteza estão irremediavelmente interligadas porque se a possibilidade de prevenção é a marca de seu gerenciamento, sua previsibilidade escapa dos modelos racionais para detê-los.

A conexão entre ordem-certeza e desordem-incerteza que compõe a organização da vida (Morin, \& Le Moigne, 2000), confirma a falência do modelo iluminista. A ordem prevista no conhecimento crescente do mundo físico e social mostrou que não se diminui a incerteza tratando o risco de forma técnica e tecnológica. Chamon e Moraes (2011) observam a importância de investigar o risco a partir de uma perspectiva psicossocial compondo o viés das possibilidades técnicas. Conhecer o risco e delimitar o problema supondo sua eliminação ou padronização em níveis aceitáveis de tolerância limita nossa capacidade de compreendê-lo. A investigação psicossocial em questões de risco serve à ampliação do conhecimento nessa área, somando as representações sociais à perspectiva tecnológica.

A representação social compreende a complexidade dos fenômenos com base na transversalidade entre disciplinas e a articulação mediada por elementos afetivos, mentais e sociais. $\mathrm{O}$ conhecimento baseado num saber científico multidisciplinar é efetivado no contexto social do senso comum (Jodelet, 2001). As representações sociais são um conceito elaborado por Serge Moscovici em seus estudos sobre a apreensão da psicanálise em 1961, onde se procurava compreender como um conhecimento científico (universo reificado) era apropriado pelo senso comum (universo consensual). Inicialmente ele recorreu às teorias de Durkheim sobre representações coletivas, mas o conceito era por demasiado estático e genérico, observando-se que os fatos sociais têm uma existência independente dos fatos individuais. Contestando essa separação, Moscovici interligou o indivíduo ao social através de um sistema de ideias, valores e práticas cujas principais funções estabelecem a ordem que permite aos indivíduos se orientar em suas realidades por meio da comunicação de códigos geradores de identidade pessoal e grupal. Procura-se estabelecer uma ordem entre o corpo e o psiquismo individual, entre as formações psíquicas e as formações grupais e as condições e os riscos da estruturação do psiquismo (Kaes, 2001).

Compreendendo que o entrelace desses fatores é essencial na compreensão da gestão de risco, na primeira parte deste trabalho será analisada a associação entre a história do risco e a responsabilidade. Para Giddens (2007), a história do risco sofreu uma modificação na passagem 
da sociedade tradicional para a sociedade moderna. Naquela, a construção de uma realidade compartilhada era mobilizada pelo temor dos riscos que a natureza impunha à humanidade, enquanto nesta a incerteza origina-se da intervenção humana sobre a natureza. A representação que a sociedade tem sobre risco e sobre a responsabilidade a ele associada não é, portanto, estática; ela acompanha a aventura do desenvolvimento individual e coletivo, define identidades pessoais e sociais, expressa os grupos e as transformações sociais de cada cultura e tempo. Observando-se uma evolução polifônica atravessada espacial e temporalmente por processos psicossociais, ainda que de maneira simplificada, optou-se por marcar o alinhamento entre risco e responsabilidade em três momentos distintos: anterior à Revolução Industrial, na Revolução Industrial e depois na reestruturação produtiva.

$\mathrm{Na}$ segunda parte deste trabalho, discute-se a emergência e o desenvolvimento da responsabilidade na interação entre a dinâmica psíquica individual e o contexto ambiental. Sob a perspectiva das teorias de Piaget e de Winnicott, considera-se a importância da interação sujeito-ambiente de trabalho na construção de uma responsabilidade internalizada, vivida como significativa e pessoal.

Por fim, na última parte, reflete-se sobre o risco dos excessos da modernidade. Com base na teoria dejouriana, compreende-se que a gestão da excelência gera uma carga psíquica em si mesma, um risco potencial para a saúde de gestores.

\section{Risco e responsabilidade: uma história indissociável}

O risco é parte da vida individual e social. A definição etimológica do conceito associa-o com a ideia de perigo, potencial de perda, incerteza, acaso, aventura, vulnerabilidade, mas também com ousadia, como ato de assumir responsabilidades e de se afirmar como pessoa (Bernstein, 1997; La Mendola, 2005). Por sua vez, conforme o dicionário Aurélio de Língua Portuguesa, responsabilidade, do latim "responsabile", compreende a obrigação de alguém para responder por atos próprios ou de outrem. Neste estudo o termo será definido como a capacidade de se preocupar e de agir considerando as consequências dos próprios atos. Assim, a relação entre risco e responsabilidade circunscreve a tensão dos processos vivos implicitamente associados a perigos e incertezas, mas também à preocupação (exigida ou sentida) com atos comprometidos com a estabilidade necessária à manutenção e continuidade do viver (Morin, \& Le Moigne, 2000). Nessa ótica, concorda-se com a afirmativa de Kierkegaard para o qual "Ousar é perder o equilíbrio momentaneamente. Não ousar é perder-se". Se correr riscos é enfrentar o desequilíbrio, não fazê-lo é manter-se limitado à repetição perdendo a chance de avançar para novos patamares.

Nos primórdios, ousar para evitar perder-se significava, sobretudo, enfrentar as intempéries naturais (Giddens, 2007). Perder era estar submetido a forças externas e arbitrárias: tempo, vento, sol, chuva. Ousar era transferir o poder para divindades da natureza, que podiam ser acalmadas com sacrifícios prescritos de acordo com cada cultura e religião. Na Grécia Antiga, avanços políticos, comerciais, sociais e técnicos conviveram por milênios com o poder dos deuses. "Reis sublimados", os deuses foram humanizados e seguiram a tendência para a unidade e para a ordem cósmica, na cultura grega sobreposta a ambos (Kitto, 1990). A ordem exteriorizada no universo mantinha a imprevisibilidade nos homens e nos deuses. Parece assombroso que os gregos, única sociedade da época não dominada por uma casta sacerdotal, se apegassem aos deuses, eles próprios seres incertos, para entender as incertezas vividas. $\mathrm{O}$ foco no indeterminado parece ter sido o que impediu o avanço da abordagem metódica do risco na época, processo que ganhou potência posteriormente, no Renascimento (Bernstein, 1997). 
Na Grécia Antiga a natureza das coisas seguia um desígnio universal. Recusava-se a distinção entre Natureza e natureza humana. Nada acontecia de maneira isolada, única ou casual: "o pano de fundo do gênero épico, significa, em última análise, que as ações particulares são, ao mesmo tempo, singulares e universais" (Kitto, 1990, p. 92). Os poderes que regiam o universo físico regulavam o universo moral. A responsabilidade pelos infortúnios humanos não advinha dos deuses, mas de sua Natureza, conforme escrito por Homero, na Odisseia:

Como os homens são tolos! Como culpam injustamente os deuses! O destino deles é sofrer, mas, devido à sua própria loucura, acarretam sobre si sofrimentos maiores do que os que o destino lhes prepara. E depois dizem que a culpa é dos deuses! (Kitto, 1990, p. 90).

Se a loucura é desordem, homens e deuses são igualmente submetidos à ordem cosmológica contada nos mitos. Com o avanço das conquistas políticas, econômicas, técnicas e filosóficas por volta do século V d.C., o mito e o conhecimento se separaram.

Progressivamente a racionalidade ganhou espaço na tentativa de compreender a vida. A teoria científica a serviço da Revolução Industrial deu um poderoso impulso à tendência crescente de quantificar e raciocinar probabilisticamente a ocorrência de todos os aspectos rotineiros da vida (Bernstein, 1997). Mas a aposta na probabilidade científica não eliminou os riscos. Transferiu-os para a inadequação humana aos avanços tecnológicos. Neboit (1999) afirma que nas análises exterioristas da organização científica do trabalho, a concepção unicausal separou os fatores técnico e humano, responsabilizando este pelos acidentes. Na insegurança vivida pelo trabalhador, fatores individuais, grupais ou psicossociais tornaram-se causas explicativas de uma predisposição humana para falhar ${ }^{3}$. Contudo, colocava-se em evidência a multicausalidade de riscos na interação entre o operador e a situação de trabalho. Na década de 1960, teorias sistêmicas passaram a explorar o acidente como um sintoma da disfuncionalidade sistêmica. $\mathrm{O}$ deslocamento favoreceu a instalação da ergonomia dos sistemas. Apoiada na teoria da confiabilidade dos sistemas, ela "desenvolve os primeiros elementos de uma análise sistêmica do trabalho e do acidente como a conseqüência da recuperação de um incidente" (Neboit, 1999, p. 3). Medidas em índices de confiabilidade, as ocorrências sinalizam o aumento da probabilidade de disfunções tecnológicas devido ao grande número de interações e à dependência entre seus elementos. A contribuição das teorias de comunicação e das teorias cognitivas apontaram as limitações humanas no tratamento de informação e na sua adaptação à complexidade sistêmica. Assim, se por incidente se compreendeu a circunstância ou episódio acidental a ser recuperado para entender e conter riscos futuros, reaver elementos perdidos ficou cada vez mais difícil no contexto complexo, flexível e fortemente competitivo da reestruturação produtiva.

Encaixada na aventura da desregulamentação ou mundo em descontrole, a reestruturação produtiva alimenta-se na busca por estabilidade em meio à instabilidade globalizante da (pós) modernidade. Tudo oscila entre estabilidade e instabilidade: o universo, os deuses e os homens. Reconsiderando a anteriormente citada afirmativa de Kierkegaard, a ousadia atual consiste mais em manter o equilíbrio momentaneamente, ousando perder-se na desordem sem sucumbir à instabilidade. O mal-estar causado pela instabilidade na complexidade reacende defesas contra perigos a serem vencidos estrategicamente, já que "só a estratégia pode ajudar a avançar no incerto e no aleatório" (Morin, \& Le Moigne, 2000, p. 149). Estrategicamente a reestruturação produtiva

3 Entre 1900 e 1950, a noção de "predisposição para acidentes" foi associada a uma "predisposição humana para falhar". Primeiramente, considerando a hipótese de grupos pluriacidentados, os estudos ressaltavam amostras estatísticas sugerindo que um pequeno número de indivíduos sofria a maioria dos acidentes. Posteriormente, os estudos recaíram sobre as variáveis individuais (idade, sexo, inteligência, personalidade) como fatores preponderantes para "correr riscos". Além disso, algumas análises observavam que determinantes ligados ao contexto familiar, profissional ou social dos grupos pluriacidentados se renovavam, orientando as pesquisas sobre fatores psicossociais intervenientes na insegurança do trabalho (Neboit, 1999). 
modificou princípios e métodos da organização do trabalho e da gerência de produção. Também atingiu os recursos humanos ao retirar-lhes garantias trabalhistas, enfraquecer movimentos sindicais e tornar os empregos instáveis, precários e estressantes. Reengenharia, flexibilidade, polivalência, estrutura mínima, enxugamento, redução, descentralização e terceirização são expressões das mudanças em curso. Riscos são associados à pressão por alta produtividade e qualidade em organizações que valorizam incessantes mudanças e rígidas regulamentações para "conquistar" a estabilidade. Metzger (2011) estudou a mudança permanente enquanto fonte de penosidade ${ }^{4}$ para o trabalhador. Partindo de dados que delatam a elevação de mortes e doenças no trabalho, conclui que os riscos estão relacionados à renovação incessante dos dispositivos técnicos e à gestão das novas formas de organização:

...se os problemas ligados aos ambientes de trabalho perigosos (poeiras, amianto, produtos químicos tóxicos, ruído, trabalho realizado em altura, dentre outros) permanecem estáveis, há uma década constata-se o crescimento dos riscos ligados à organização do trabalho (Metzger, 2011, p. 13).

Para o autor, pesa sobre os trabalhadores a intensificação do trabalho, com ritmos elevados e prazos restritos, além de sua responsabilização num contexto de enfraquecidas solidariedades profissionais. Pressionado a se responsabilizar pela perspectiva de excelência em curso o trabalhador culpa-se pelos fracassos mesmo sem condições para atender às exigências feitas:

...os trabalhadores interiorizam as injunções gerenciais de serem "os responsáveis". "Tomam para si”, sentem-se responsáveis por seus fracassos (culpabilidade), ainda que devam realizar tarefas "impossíveis" (objetivos irreais, ausência de formação adaptada, impossibilidade de testar) ou executar atividades cujos procedimentos são inadequados (ferramentas ou procedimentos incompatíveis, trabalho coletivamente realizado, mas individualmente avaliado, interrupções frequentes) ou, ainda, efetuar tarefas inúteis (perda do sentido) (Metzger, 2011, pp. 13-14).

Nesses parâmetros o ambiente de excelência da restruturação produtiva neoliberal gera condições adversas à emergência e/ou manutenção de uma responsabilidade baseada em julgamentos morais autônomos, vividos como verdadeiros e pessoais quando a culpa dá lugar à capacidade de se preocupar com o outro. De fato, na gestão da excelência, ou qualidade total, emergente dos modelos produtivos americanos da década de 1980, destaca-se a exigência de um comprometimento maciço e uma adesão passional do trabalhador, traduzida na "mobilização total do indivíduo a serviço da organização" (Chanlat, 2000, p. 121). Tomando como perspectiva a teoria cognitiva de Piaget e a teoria psicanalítica de Winnicott, segue-se na análise do impasse anunciado.

\section{A interação sujeito-ambiente na construção da responsabilidade}

Na abordagem genético-cognitiva de Piaget o desenvolvimento cognitivo e a formação da consciência moral resultam da interação do indivíduo com o ambiente social. Assimilação de estímulos externos e de acomodação na estrutura cognitiva ${ }^{5}$ são processos ativos e organizados

4 O termo pénibilité, esclarecido em nota de rodapé pelo tradutor, está em construção nas ciências sociais francesas para cunhar uma especificidade associativa com a degradação das condições de trabalho da atualidade.

5 Acomodação na estrutura cognitiva refere-se à expressão que Piaget extrai da Biologia para designar a mudança dos esquemas cognitivos e sensório motores, provocada por conteúdos externos. Na assimilação, o conteúdo se adapta aos esquemas existentes (Wadsworth, 1996). 
progressivamente na vida individual, podendo ser estimulados ou inibidos pelo ambiente. Inserida no contexto neoliberalista e na reestruturação produtiva, a responsabilidade tem uma função, simultaneamente, mentalizada e socializada (Jodelet, 2001). Parâmetros éticos e normas sociais que fundamentam concepções, julgamentos morais e ações produtivas vigentes relacionam-se com o amadurecimento cognitivo individual e o equilíbrio sociocognitivo em curso.

Com base no trabalho de Piaget Le jugement moral chez l'enfant, publicado em 1932, Penna (1995) confronta o utilitarismo com o formalismo ético kantiano. Para ele, a rejeição ao modelo neoliberal justifica-se na análise genético-cognitiva devido ao modelo da ética utilitarista centrada em resultados: "...pelas pesquisas empíricas por ele (Piaget) realizadas desqualifica-se o suporte moral do neoliberalismo como primitivo e infantil" (Penna, 1995, p. 161).

O capital que corria o risco de esmorecer antes da Guerra Fria ousou expandir-se pelo mundo anunciando a cooperação entre países. No entanto, com o aumento da competição, as ameaças parecem brotar do interior do próprio sistema, apontando sua imaturidade. Por exemplo, princípios éticos de autonomia avançaram em acordos de responsabilidade social organizacional (RSO), com a luta de alguns para não ser uma imagem vazia e mascarada na burocrática gestão da excelência (Domingos, 2007). Além disso, a despeito de ganhos relacionados à complexidade, a produtividade competitiva organizada nas fábricas neo-tayloristas seguiu rígidos padrões de produção mantendo a estagnação do processo cognitivo em níveis inferiores de raciocínio:

OCCQ (Círculo de Controle de Qualidade), introduzido na administração moderna como instrumento do desenvolvimento do raciocínio e da criatividade, apresenta as características de padronização de raciocínio em nível do pré-operatório, portanto, mantendo o indivíduo num nível mental em que ele só conseguirá pensar a ação concreta... (Aguiar, 2005, pp. 259-260).

O discurso neoliberal solicita a autonomia nas relações de cooperação, igualdade e respeito mútuo para impedir o risco de falência capitalista; ele exige a responsabilidade comprometida com as consequências dos atos próprios. Na prática, favorece a heteronomia, o raciocínio concreto das regras obrigatórias, o respeito e a responsabilidade unilateral típicos da relação autoritária externa. Embora se exija a autogestão, prevalece o ambiente inibitório da capacidade do agir responsável. A responsabilidade que é inerente à natureza humana não tem terreno fértil para proliferar.

Para Winnicott (1983) a responsabilidade é instituída no estágio de preocupação, após a integração da posição depressiva ${ }^{6}$, quando a vivência do sentimento de culpa e de compaixão organiza um terreno propício à educação moral. $\mathrm{O}$ ambiente provê ou inibe condições para desenvolver o potencial inato. Num "ambiente suficientemente bom", adaptado ativamente às necessidades da estruturação psicossomática, impulsos agressivo-destrutivos da constituição individual são reconhecidos e respeitados pelas figuras centrais do desenvolvimento. A sobrevivência objetal cria condições para transformar parte da agressividade em culpa e em conflitos conscientes e inconscientes vividos na satisfação de preocupar-se com o outro: "A atividade social não pode ser satisfatória a não ser quando se baseia num sentimento de culpa pessoal a respeito da agressividade" (Winnicott, 1983, p. 291). Felizmente a maioria das pessoas vivencia essa experiência, fato que permite, por exemplo, a sobrevivência do próprio capitalismo.

Morse (1988) considerou que estudos sobre famílias ricas no tempo dos capitalistas provinciais indicam que os fundamentos morais da perseguição ao lucro a qualquer preço eram considerados suspeitos e até imorais. Atualmente, para uma parte dos empresários, a RSO seria um modo conscientizado de reparar os danos causados à imensa maioria da humanidade

6 O termo posição depressiva difere de depressão, esta um processo patológico, vivido como despersonalização ou desesperança quanto aos relacionamentos objetais, aquela estruturante na medida em que, ao se identificar com o outro, o ego garante sua própria preservação. 
(Domingos, 2007). A reparação, que podia tomar outros rumos reflexivos, nesse caso é a capacidade de "reconhecer, tolerar e conter o sentimento de culpa" (Winnicott, 2000, p. 156), permitindo a fusão da agressividade com seu componente erótico. Num ambiente intrusivo e inflexível para acompanhar as necessidades do desenvolvimento, a adaptação ao contexto pouco confiável dificulta tal processo. O deslocamento da força vital culmina com a produção do "falso self”, cuja versão patológica caracteriza um estado de submissão, dissociação, falta de sentido e descontinuidade.

A responsabilidade adaptada a princípios de gestão rígidos com tarefas impossíveis e inúteis (Metzger, 2011) produz frustração e sentimento de inutilidade em um ambiente tantalizante. Reconhecido como valor estratégico, o trabalhador perde seu pódio tão logo as oscilações do mercado se manifestem. Para Goméz (2006), essa lógica é mais grave ainda para profissionais que operam com riscos. Expostos com frequência a situações de intenso impacto, eles sofrem a pressão de cargas horárias irregulares e extensas em momentos de pico, exposição a situações arriscadas e de vulnerabilidade individual e grupal que podem interferir negativamente em sua saúde física e mental.

\section{Carga psíquica na gestão da excelência: a lógica da totalidade no repositório do desgaste psíquico}

A gestão da excelência, desde os anos 1980, tem sido adotada como método inovador no controle e para enfrentar as incertezas e os perigos de uma sociedade industrial altamente tecnológica e interdependente. Nesse caso, o que ronda o mundo produtivo e que anuncia uma ameaça sistêmica a ser evitada é a competição do mercado nacional e internacional. Para Chanlat (2000) a necessidade de produzir melhor que a concorrência valoriza o modelo da excelência cuja prioridade é baseada no êxito, na atividade exacerbada, na intensa adaptação e no desafio constante. $\mathrm{O}$ incentivo a um poder total, coincidente com o imaginário de invulnerabilidade, remete à ideia de perfeição extenuante e perigosa podendo, inclusive, alimentar a negação de riscos de acidentes. A excelência incorporada à sobrevivência do sistema organizacional exige do indivíduo a obrigação de ser forte, capaz, autônomo, responsável, flexível e polivalente no trabalho. Considerando-se a positividade desse processo, tal perspectiva valoriza e reconhece as pessoas e a individualização de seu desempenho. Porém, tendo como particularidade o envolvimento total de cada componente, o aspecto negativo dessa gestão salienta o comprometimento excessivo a exigir o empenho pleno do sujeito: "a mobilização total do indivíduo a serviço da organização... este último fator canaliza a energia física, afetiva e psíquica de seus membros" (Chanlat, 2000, p. 121)

Frutuoso e Cruz (2005) salientam que a compreensão do termo carga de trabalho resulta da tensão gerada entre as exigências produtivas e as capacidades biológicas e psicológicas para atendê-las. Carga de trabalho envolve fatores nocivos e fatores de risco interligados para descrever riscos ocupacionais que podem incidir sobre a saúde do trabalhador. Identificam-se fatores "... físicos (condições do ambiente), psíquicos (afetivos e emocionais) e componentes cognitivos (atenção, memória, tomada de decisão etc.)" (Frutuoso, \& Cruz, 2005, p. 32).

Dejours (1994), autor cuja ênfase é o sofrimento no trabalho, observa que a separação entre carga física e carga mental de trabalho está associada à noção de carga em ergonomia, baseada em modelos quantitativos e objetivos. No entanto, "tratando-se de carga psíquica, não é possível quantificar uma vivência, que é em primeiro lugar e antes de tudo qualitativa. O prazer, a satisfação, a frustração e a agressividade, dificilmente se deixam dominar por números" (Dejours, 1994, p. 22). 
Se numericamente não é possível medir a carga psíquica, sua existência evidencia-se concretamente em absenteísmo, greves ou até no engajamento laboral patológico. Guimarães, Coêlho e Caetano (2004) ressaltam que o ritmo acelerado da nova onda econômica determina o aumento de estresse, podendo até provocar a morte por excesso de trabalho. Traduzido inicialmente como "morte súbita ocupacional", Karoshi tem sido reconhecida como uma carga excessiva de trabalho capaz de adoecer e matar o trabalhador. $O$ fenômeno começou no Japão e já é um problema mundial. Análise dos casos japoneses indicaram fatores de risco do quadro: muitas horas de trabalho, deslocamento para o local de trabalho e cronogramas irregulares de produção. A recessão mundial, mudanças estruturais na indústria e no sistema tradicional de emprego produzem estresse e fatores psicológicos que associados à cultura paternalista e à tendência excessiva para o trabalho contribuem para esse mal. Trabalhadores mais vulneráveis são os que se sentem sob "ameaça imediata se o trabalho exige esforço mental extremo e têm prazos a serem cumpridos". A adoção do modelo individualista pela cultura japonesa também adoece: “...o estresse também se acumula quando o trabalhador tem que trabalhar de forma independente, por iniciativa própria, sem a assistência dos colegas" (Guimarães, Coêlho, \& Caetano, 2004, p. 91).

Com base nos estudos psicossomáticos da escola de Pierre Marty, Dejours (1994) separa aspectos positivos e negativos da carga psíquica do trabalho. Ela é positiva se permite vias de descarga adaptadas às atividades psíquicas, fantasmáticas e psicomotoras do trabalhador. Inversamente, o perigo de uma sobrecarga psíquica está associado ao subemprego desses recursos, o que ocasionaria a retenção da energia pulsional do indivíduo. A elevação dos níveis da carga psíquica está na incapacidade de escoar satisfatoriamente a tensão, bem como na estrutura da personalidade constituída na história individual, na organização do trabalho e no grau de liberdade que a tarefa a ser realizada permite produzir.

No que tange ao trabalho de risco de policiais, Minayo, Souza e Constantino (2007) observam que a consciência do risco, implícita nas suas atividades, pode ter papel estruturante para eles, para o ambiente laboral e suas relações sociais. O problema é quando a pesada carga de trabalho e de sofrimento vividos por esses profissionais supera o desgaste físico e mental do restante da sociedade (Minayo, Assis, \& Oliveira, 2011). Particularidades dessa atividade podem por si mesmas ser excitatórias do aumento da carga psíquica. Para Gómez (2006) o gestor de riscos tem uma sobrecarga extra porque está submetido a situações de intenso impacto, pressão de cargas horárias irregulares e extensas em momentos de pico, exposição a circunstâncias arriscadas e de vulnerabilidade individual e grupal e outros problemas.

Além disso, num intrincado processo de modernidade, a gestão da excelência impõe um peso particular a essa vivência, ao incutir a migração do fazer coletivo para um fazer individual e a responsabilidade compartilhada para outra, autoimposta:

\footnotetext{
Não são mais as categorias que se encontram confrontadas às situações idênticas de trabalho, a idênticas coerções, a uma mesma lógica de dominação, que é coletiva por natureza. É o indivíduo que está sozinho em face desta nova forma de dominação e face às contradições que ela carrega. E ele procura assumir estas pressões, persuadido no fundo de si mesmo que são suas próprias insuficiências que tornam sua missão tão difícil e não as contradições inscritas na própria organização (Linhart, 2000, p. 34).
}

A importância de estratégias defensivas individuais e coletivas para lidar com as intempéries organizacionais tem sido debatida pela psicodinâmica do trabalho. Do lado individual, elas protegem-no contra o próprio sofrimento e as pressões do real laboral. No entanto, é na coletividade, no grupo, por meio da negociação e do consenso, que a vivência - individual e coletiva - das pressões organizacionais se suaviza e a estabilidade do todo organizacional consegue se manter: "as 
estratégias defensivas contribuem para assegurar a coesão e a construção do coletivo de trabalho, ou seja, também a cooperação com vistas a atender os objetivos fixados pela organização do trabalho" (Dejours, 1994, p. 132).

Portanto, se a competição exacerbada, a instabilidade permanente e a exigência da submissão total do sujeito aos novos modelos de gestão moderna recaem prioritariamente sobre o indivíduo, isso o torna mais vulnerável ao acidente e/ou adoecimento. Nesse caso, se é certo que o risco faz parte da vida, relações de trabalho perversas e/ou precarizadas potencializa a possibilidade de acidentes e de incidentes se tornar mais corriqueira.

\section{Método}

\section{Participantes}

A amostra contou com dez gestores de risco de organizações públicas e privadas, assim distribuída: 5 do setor de Petróleo e Gás, 3 da Segurança Pública do Estado do Rio de Janeiro, 1 do setor de investimentos e 1 da área de gestão de multidões e grandes eventos. Os participantes, na sua maioria, eram do sexo masculino, com curso superior completo e idades entre 30 e 55 anos. Para finalização da amostra, obedeceu-se ao critério de saturação quando é possível fechar um corpo de análise consistente no momento em que denominadores comuns são encontrados em seus discursos e as informações tendem à repetição de dados já obtidos (Fontanella, Ricas, \& Turato, 2008).

\section{Instrumentos de Coleta de Dados}

Seguindo-se o método de explicitação do discurso subjacente (MEDS) proposto por Nicolacida-Costa (2007), realizaram-se duas entrevistas abertas e oito com roteiros estruturados, aplicados de forma flexível. Em duas entrevistas exploratórias e abertas (1 da área de investimentos e 1 de Petróleo e Gás), observou-se a associação livre para capturar o discurso espontâneo e o sentido da vivência de risco dos participantes. Esse conteúdo serviu como base para elaborar as entrevistas semiestruturadas, aplicadas em ambientes escolhidos pelos entrevistados.

\section{Comité de Ética}

Este texto decorre do projeto de iniciação científica "Representações sociais da gestão de risco: limites sob a ótica do trabalhador", submetido ao Comitê de Ética em Pesquisa da Universidade Veiga de Almeida (UVA) e liberado pelo protocolo número 02876312.6.0000.5291.

\section{Análise de resultados e discussão}

Os depoimentos das entrevistas foram submetidos à análise de conteúdo, tendo como princípio o reconhecimento de níveis abstratos emergentes do texto, classificados por temas e organizados em blocos de significação para a construção de categorias empíricas de análise. Seguindo orientações do MEDS, os depoimentos foram analisados em duas etapas: a) a análise interparticipantes, das respostas dadas pela totalidade da amostra oferecendo uma visão do todo pesquisado; b) a análise intraparticipantes, cujo detalhamento das entrevistas individuais permite uma análise aprofundada. Ainda de acordo com o MEDS, a interpretação dos dados considerou duas abordagens: a) êmica, caracterizada por categorias que surgiram das falas dos entrevistados e 
b) ética, de categorias prévias oriundas do aporte teórico multidisciplinar que serviram de base a essa pesquisa (Nicolaci-da-Costa, 2007). Destaca-se a seguir a análise das categorias emergentes mais significativas deste trabalho.

a) $\mathrm{O}$ risco associado à vivência de perigo: na gestão de risco, a cena de perigo conduz a vida profissional. Na obra A loucura do trabalho, Dejours (1992) observa a "contaminação" do tempo no trabalho e fora dele, formando uma difícil dissociação, visto nos seguintes recortes: ...você está aqui e tem o risco desse teto cair na sua cabeça então como você minimiza isso, fazendo trabalhos de manutenção, vistoria... ele (o risco) está sempre presente, onde você está, tem risco, você tem o risco agora de levar uma bala perdida (A2); Risco, você pode estar no banheiro da sua casa, tomar uma queda e cair no chão e bater a cabeça e morrer, entendeu (B2). A naturalização e banalização do sofrimento aqui demarcadas advêm, na teoria dejouriana, de mecanismos de defesa inconscientes num processo que reflete o esforço de adaptação do sujeito ao contexto do trabalho, de risco, neste caso.

b) A administração do risco na gestão moderna: na sociedade moderna, se por um lado a inovação tecnológica e novos métodos de gestão favorecem o alargamento do capital, também os riscos fabricados ganham volume (Giddens, 2007) e a capacitação permanente é vista como essencial: À medida em que a sociedade vai se tornando cada vez mais tecnológica os riscos vão mudando de natureza, você começa a ter um monte de riscos à sua volta que você sequer conhece, então se preocupar com isso é cada vez mais importante (A1); Eu sou uma pessoa muito ansiosa, mas eu procuro fazer treinamento, eu tento fazer todos os cursos operacionais que eu possa fazer e não só na área operacional, como na tecnologia também (B3). Fica claro que a capacitação para os riscos num contexto de incerteza não é meramente técnica, mas coloca em jogo um processo de "ansiedade" para adquirir conhecimentos e habilidades que os ajude a enfrentar os intempéries e as inovações, operacionais e tecnológicas da atualidade.

c) O risco como senso de responsabilidade: a vigília aguçada acompanha a vida desse trabalhador, tornando-se um valor. $\mathrm{O}$ sentimento de preocupação integrado ao ego é um aspecto positivo da responsabilidade internalizada (Winnicott, 1983): ...quando você entra em um carro e bota um cinto de segurança, tem muita gente que bota o cinto porque se andar sem cinto o guarda vai multar e tem aquela pessoa que já vê da seguinte forma: "eu boto isso aqui porque isso aqui é a minha vida, é a minha segurança" então isso é um valor para mim (A4). Assim, a ordem opera, mantém e reforça práticas de segurança bem como compõe estratégias individuais e coletivas de defesa (Dejours, 1994): Ele (o trabalho em gestão de riscos) se torna mais complexo até por conta que você passa a depender da atividade das outras pessoas, ou seja, você tem várias pessoas envolvidas ou numa unidade, num projeto ou numa ação e que uma falha dessa pessoa pode vir a comprometer a saúde e a vida das demais pessoas, então é uma atividade que faz com que a responsabilidade de cada um aumente ainda mais e faz você ter uma maior percepção/observação, maior cuidado com essa atividade (A2).

d) A carga psíquica em profissionais de risco: segundo Minayo et al. (2011) a carga de trabalho e de sofrimento vivida por profissionais de risco deixa de ser positiva quando se torna um desgaste físico e mental superior ao vivido pela sociedade em geral. As atividades deles podem gerar sofrimento excessivo porque a falha, o erro, pode ter desdobramentos imprevisíveis a serem evitados: ...é uma atividade que você não pode falhar, você não pode errar, um pequeno erro, uma pequena falha pode causar um acidente que na atual conjuntura pode vir a quebrar a sua empresa dependendo do 
acidente, dependendo do local em que ele ocorra, dependendo da magnitude... (A4); ...então quando se fala em atividade de risco, é você estar 24 horas caminhando em cima de uma navalha (A2). Expressa na (im) possibilidade de falha pessoal está a máxima do gerenciamento da excelência a incutir o perfeccionismo extremo aos trabalhadores (Chanlat, 2000). Lidar com o risco é contraditório porque inovar envolve erros e experimentação: ...chega uma hora que você tem que assumir riscos, ... a humanidade caminha superando riscos, se não você vai, se ficar paralisado, "só vou fazer o que é seguro", você acaba não fazendo nada, você não rompe barreiras, não evolui (C1).

e) A potencialidade do risco do adoecer no trabalho: a ansiedade (em intensidades moderadas) pode ser produtiva ao colocar o sujeito numa posição de enfrentamento de situações perigosas, reais ou imaginárias. Porém, se não é possível uma descarga psíquica adequada, o sujeito pode ser acometido de angústia, somatizações, desligamento do trabalho ou da própria vida (Dejours, 1994): Eu conheço diversos colegas que tiveram ataque de pânico?. Eu já passei por inúmeras situações de risco... eu tive um ataque de pânico lá, e só depois eu vim a saber o que é ataque de pânico, mas eu congelei na minha cama e dizia: eu não quero mais sair de casa, eu não quero mais... eu tive um surto naquele momento dentro de casa e minha esposa: o que houve? O que houve? E eu não sabia o que era (B2). Em meio à obrigação de tudo saber (das consequências dos riscos), ele sofre porque algo foge de seu controle. Nesse caso, a organização da excelência que investe narcisicamente o sujeito (Chanlat, 2000; Enriquez, 1997), valorizando sua responsabilidade para enfrentar os perigos, não lhe oferece amparo quando a intensificação das defesas contra o adoecer se tornam limitadas.

A interpretação dos depoimentos interparticipantes evidenciou que na categoria "carga psíquica em profissionais de risco", sobre o profissional de Segurança Pública, o desgaste físico e mental é particularmente intenso em relação a dos outros grupos pesquisados, fato corroborado por Minayo et al. (2011). O significado do risco na existência humana revelou similaridades na amostra da pesquisa. Os entrevistados foram unânimes na interpretação do risco como uma possibilidade da vida: probabilidade de acontecer alguma coisa, boa ou ruim (C1); possibilidade de ocorrência de materialização do perigo, ou vulnerabilidade dependendo da interpretação (A1); e a nossa vida já é um risco (B3). Porém, no grupo de Segurança Pública, a associação entre risco e perigo ganhou relevo e foi ostensivamente ligada à morte: uma situação de iminente risco mesmo, de morte (B2). Neles, o perigo atravessa todas as instâncias (pessoal, populacional e familiar) da vida: não tem como a gente privar as pessoas de andar na rua em uma operação (B1); às vezes não é nem a operação em si, você está voltando para casa e o cara te reconhece e fala que vai te matar, às vezes passeando com a família, você esquece alguma coisa dentro do seu carro e volta para pegar e daí te matam" (B2). Presume-se que, para manter o equilíbrio psíquico, esse grupo demanda fortes estratégias de defesas individuais e coletivas (Dejours, 1994): eu tenho um medo que me move a não dar mole, mas eu não penso nisso, eu respiro fundo e parto para dentro, para fazer o que tem que ser feito, entendeu?... a gente trabalha em conjunto... tomamos decisões em conjunto" (B1). O enfraquecimento defensivo pode gerar desequilíbrios psicossomáticos, doenças mentais e/ou estresse, no âmbito individual "ataque de pânico, vários já tiveram" (B2) ou comportamentos estereotipados e/ou alienados quando as defesas coletivas falham: quando você tem uma perda de um policial você tem uma perda psicológica na equipe, depois de 5, 10 anos, você vê que a realidade é outra, então fica todo mundo desanimado (B3).

7 A menção ao ataque de pânico pelo entrevistado pode, ou não, ter correspondência com o Transtorno de Pânico. Segundo a Classificação Estatística Internacional de Doenças e Problemas relacionados com a Saúde, o CID-10, o Transtorno do Pânico ou Ansiedade Paroxística Episódica caracteriza-se por ataques recorrentes de ansiedade intensa, em circunstâncias imprevisíveis. A sensação de perda de controle, sudorese, medo de morrer são algumas das manifestações desse quadro, que pode ser desencadeado por situações intensas de estresse. Porém, o estudo não visou esclarecer esse ponto. 
O comprometimento da organização pública com seu colaborador é inconsistente com a imagem divulgada: não tem comprometimento nenhum, entendeu? O poder público não se preocupa com a vida do policial, se tem um bom salário, não querem saber se a vida dele está legal, eles não querem saber como eles estão trabalhando, se o próprio local de trabalho tá bom, só quer saber de mostrar para todo mundo, pegar as viaturas e botar nas ruas para o pessoal ver (B3). Retomando Winnicott (1983), se o ambiente organizacional do grupo não é percebido como confiável, a transformação da força vital dos impulsos agressivo-destrutivos em responsabilidade fica comprometida. Sentimentos de submissão, dissociação e desesperança podem ser o único meio de sobreviver num contexto onde o trabalho enquanto fato social determinante no processo saúde/doença é ignorado. Especificamente em relação aos policiais, Minayo et al. (2011) destacam a insistência deles para que suas corporações instituam formas eficazes de apoio psicossocial a seus membros. A demanda se justifica porque comparado com outros países, dados demonstram que no Brasil eles sofrem mais intensamente e, em maiores proporções, com agravos à sua saúde. Tomando o Rio de Janeiro como referência, além do estresse laboral esse grupo também apresenta taxas de mortalidade e de morbidade por causas externas superiores as de outros grupos populacionais.

No ambiente de Petróleo e Gás, nos depoimentos dos interparticipantes, o principal agravo levantado foi a interferência da "cultura na gestão de risco". No intrincado imaginário cultural, a percepção sobre risco mistura aspectos nacionais e institucionais e exige trabalho: ...temos ainda no imaginário de todos os brasileiros, que a gente não tem ameaças... na empresa, há pelo menos dez, quinze anos que se tenta mudar essa visão, essa cultura, a mudança de cultura é algo muito lento (A3); ...então você tem que usar métodos andragógicos... o trabalho que eu fiz com caminhoneiros foi assim (A1). A responsabilidade nesses gestores foi associada à natureza (perigosa) de sua atividade e à necessidade de antecipar os efeitos negativos do risco: .... indústria de óleo e gás é uma indústria de risco em todos os sentidos, tanto o risco financeiro/tecnológico quanto o risco de acidentes, então é da natureza dela o risco, então sempre se trabalhou e investiu muito nessa questão e ultimamente mais ainda por conta dos desafios tecnológicos que temos pela frente... é você se preocupar em antecipar os riscos, conhecer os riscos a que você está sujeito (A1). Embora a antecipação dos riscos possa gerar tensão psíquica, isso não é necessariamente fonte de adoecimento. Para Dejours (1992), se um trabalho permite a redução da carga psíquica, ele é equilibrante; se ele se opõe a essa diminuição, há um acúmulo de carga psíquica e um esgotamento de energia, gerador de uma "agressão psíquica". A análise intraparticipante apontou um possível escoamento energético equilibrante direcionado para o trabalho: ...teoricamente ele (ser humano) está sujeito a vários riscos... ele não pode ter uma paranoia de estar o tempo todo preocupado com esses riscos que estão envolta dele... o fato dele (risco) estar presente é interessante porque ele te obriga a se manter o tempo todo ligado, preparado, atento a esse risco, faz com que você mantenha a sua mente o tempo todo trabalhando por conta disso... Como a gente trabalha com isso, nós ficamos de certa forma mais ligados do que as outras pessoas, ou seja, a gente fica preocupado com a percepção de risco, a falta de percepção de risco (A2). O desgaste, nesse grupo, é interpretado como oriundo de fonte externa, de organizações e indivíduos fora da cultura de redução dos riscos, nesse caso circunscrita à gestão da excelência. Em geral adotada por grandes companhias, a lógica perfeccionista amparada por normas e procedimentos parece operar uma cisão, sendo o risco interno, controlado e o risco não controlado projetado externamente, a ser supervisionado naqueles que não aderem a essa cultura: ...se você tem uma empresa como um todo organizacional (que) está preocupada com a gestão de risco, você vai ter normas, procedimentos, treinamento, modo de fazer, acompanhamento, supervisão, então o trabalho segue uma estrutura organizacional. Você tem empresas que não têm essa visão ainda, empresas menores, e aí depende muito da proatividade dos empregados e depende de como a supervisão encara aquilo, se acham que é bom ou atrapalha (A1). Quando do lado interno a questão da vulnerabilidade é admitida, a tensão é localizada nos desafios do trabalho interdisciplinar: Pensar em gestão de risco, sem pensar em equipe 
interdisciplinar, sem pensar em envolver várias áreas, não dá. Porque é um trabalho que é complexo em sua natureza, então é assim, é um trabalho que precisa envolver mais pessoas (A3). Considerando a importância da dinâmica do trabalho em equipes interdisciplinares na gestão de risco, esse ponto mereceria uma investigação mais profunda. Porém, não possuímos material para avançar nessa discussão.

\section{Considerações finais}

A investigação da experiência de gestores de risco permitiu identificar altos índices de ansiedade que a cobrança interna (pessoal) e externa (organizacional, familiar e social) para antever as incertezas e os perigos mobiliza na vida do profissional. Nas atividades de risco a clareza sobre a própria responsabilidade é relevante. A ordem (risco-causa-consequências) que opera para a manutenção e o reforço de práticas de segurança e da percepção sobre riscos, muitas vezes negligenciada pela maioria das pessoas, é parte integrante das cobranças que não podem ser esquecidas pelos que devem antecipar os desastres intrínsecos à sociedade de riscos.

A tentativa da previsão de eventos que já foi vista como um apelo aos deuses, portanto sem resolução no conhecimento terreno, foi invertida com os avanços científicos. A mudança da relação vertical (homem-Deus) para um eixo horizontal (homem-homem) foi um marco para o princípio da gestão de riscos, com o conhecimento de cálculos probabilísticos antecedendo a ocorrência de certos eventos. Mas esse processo foi também a entrada em uma nova fase, com a maior responsabilização do indivíduo sobre os acontecimentos.

A ansiedade transformada em responsabilidade é inerente à ousadia que acompanha a vida. Observa a mobilidade saudável na constituição psíquica do sujeito implicado com concepções morais que prezam as relações de cooperação e de autonomia. $\mathrm{O}$ ambiente tem papel significativo nesse processo, podendo facilitar ou dificultar a vivência de mecanismos de construção e de destruição que acompanham a trajetória da existência. Nesse caso, ignorar as contradições e conflitos que advém das organizações reduz o debate de enfrentamento de riscos à culpa individual isentando os dirigentes capitalistas de incorporar à gestão medidas preventivas de contenção de riscos.

O capitalismo vigente, escamoteado em gestão de excelência, cria um ambiente que alude à fantasia de tudo poder ser controlado. No entanto, não é possível que um sistema garanta cem por cento de segurança, que todas as vidas sejam salvas ou que a rentabilidade, a relação custo-benefício, seja sempre positiva. A responsabilidade disparada pelo topo das hierarquias das organizações, incluindo o próprio Estado, é cobrada individualmente por resultados favoráveis à contenção das ameaças do sistema. Mas esse mesmo sistema vem diluindo os mecanismos coletivos de amparo social e intensificando o ritmo de trabalho e de estresse. O gestor de risco que tem em sua atividade a possibilidade de elaboração psíquica e fantasmática passa a viver o desequilíbrio quando a nova onda econômica exige sua adesão total, sua adaptabilidade constante, sua permanente obrigação de ser forte ou subaproveita sua capacidade de se responsabilizar, sua necessidade de refletir e de criar novos significados. Porém, o ambiente organizacional deve oferecer condições (de trabalho, lazer, organizacionais, políticas, familiares, sociais entre outras) para que os (inevitáveis) riscos da sociedade em geral e do trabalhador em particular possam ser geridos.

Esta investigação apresenta limitações especialmente no que tange à discussão sobre o próprio processo de trabalho, suas regras prescritas e não prescritas. A possibilidade de ampliar os dados aqui expressos com estudos de caso que possam esclarecer os riscos inerentes ao processo de trabalho, as normas de gerenciamento dos riscos adotados pelas organizações, como os trabalhadores lidam com elas para maximizar a segurança e minimizar as cargas de trabalho seria imensamente proveitosa. 


\section{Referências}

Aguiar, M. A. F. (2005). Psicologia aplicada à administração: uma abordagem interdisciplinar. São Paulo: Saraiva.

Bernstein, P. L. (1997). Desafio aos deuses: a fascinante história do risco. Rio de Janeiro: Campus.

Chanlat, J.-F. (2000). Modos de gestão, saúde e segurança no trabalho. In E. Davel, \& J. Vasconcelos (Orgs.), "Recursos" humanos e subjetividade (3a ed., pp. 118-128). Petrópolis, RJ: Vozes.

Chamon, E. M. Q. O., \& Moraes, P. M. (2011). A representação social do risco em atividades potencialmente perigosas. Temas em Psicologia, 19 (1), 243-252.

Dejours, C. (1992). A loucura do trabalho (5a ed. ampl.). São Paulo: Cortez. (Originalmente publicado em 1987)

Dejours, C. (1994). A carga psíquica do trabalho. In C. Dejours, E. Abdoucheli, \& C. Jayet (Orgs.), Psicodinâmica do trabalho: contribuições da escola dejouriana à analise da relação de prazer, sofrimento e trabalho (pp. 21-32). São Paulo: Atlas.

Domingos, M. L. C. (2007). Responsabilidade social nas organizações de trabalho: benevolência ou culpa? Psicologia, Ciência e Profissão, 27 (1), 80-93.

Enriquez, E. (1997). A organização em análise. Petrópolis, RJ: Vozes.

Ferreira, A. B. (2010). Dicionário da língua portuguesa (5aㅡ ed.). Curitiba: Positivo.

Fontanella, B. J. B., Ricas, J., \& Turato, E. R. (2008). Amostragem por saturação em pesquisas qualitativas em saúde: contribuições teóricas. Cadernos de Saúde Pública, 24 (1), 17-27.

Frutuoso, J. T., \& Cruz, R. M. (2005). Mensuração da carga de trabalho e sua relação com a saúde do trabalhador. Revista Brasileira de Medicina do Trabalho, 3 (1), 29-36.

Giddens, A. (2007). Mundo em descontrole: o que a globalização está fazendo de nós. Rio de Janeiro: Record.

Goméz, C. (2006). Saúde mental na gestão dos desastres: intervenção no cotidiano e nos eventos. In Cartilha do 1ํㅡ Seminário Nacional de Psicologia das Emergências e dos Desastres: contribuições para a construção de comunidades mais seguras. Brasília: Finatec/UnB.

Guimarães, L. A. M., Coêlho, A. E. L., \& Caetano, D. (2004). Karoshi: morte por sobrecarga de trabalho. In L. A. M. Guimarães, \& S. Grubits (Orgs.), Série saúde mental e trabalho (vol. 3, pp. 79-94). São Paulo: Casa do Psicólogo.

Jodelet, D. (2001). Representações sociais: um domínio em expansão. In As representações sociais (pp. 17-44). Rio de Janeiro: UERJ.

Kaes, R. (2001). Psicanálise e representação social. In D. Jodelet (Org.), As representações sociais (pp. 67-90). Rio de Janeiro: UERJ.

Kimura, H., \& Perera, L. C. J. (2005). Modelo da otimização da gestão de risco em empresas não financeiras. Revista Contabilidade Ë Finanças, 16 (37), 59-72.

Kitto, H. D. F. (1990). Os gregos (Coleção Stvdivm, 3ạ ed.). Coimbra: Arménio Amado.

La Mendola, S. (2005). O sentido do risco. Tempo Social, 17 (2), 59-91. (Originalmente publicado em 1999. Título original: Il senso del rischio)

Linhart, D. (2000). O indivíduo no centro da modernização das empresas: um reconhecimento esperado mas perigoso. Trabalho e Educação, 7, 24-36.

Mendes, R., \& Dias, E. C. (1991). Da medicina do trabalho à saúde do trabalhador. Revista de Saúde Pública, 25 (5), 341-349.

Metzger, J.-L. (2011). Mudança permanente: fonte de penosidade no trabalho. Revista Brasileira de Saúde Ocupacional, 36 (123), 12-24.

Minayo, M. C. S., Souza, E. R., \& Constantino, P. (2007). Riscos percebidos e vitimização de policiais civis e militares na (in)segurança pública. Cadernos de Saúde Pública, 23 (11), 2767-2779.

Minayo, M. C. S., Assis, S. G., \& Oliveira, R. V. C. (2011). Impacto das atividades profissionais na saúde física e mental dos policiais civis e militares do Rio de Janeiro. Ciência E̊ Saúde Coletiva, 16 (4), 2199-2209.

Morin, E., \& Le Moigne, J. L. (2000). A inteligência da complexidade. São Paulo: Fundação Peirópolis.

Moulin, M., \& Moraes, A. (2010). Vamos fazer poeira! Fontes e expressões de pressão no trabalho do setor de rochas ornamentais no Espírito Santo. Revista Brasileira de Saúde Ocupacional, 35 (122), 192-200. 
Morse, R.M. (1988). O espelho de próspero: cultura e ideias nas Américas. São Paulo: Companhia das Letras.

Neboit, M. (1999). Abordagem dos fatores humanos na prevenção de riscos do trabalho. In Conferência Gestion Scientifique du Risque (I. M. Almeida, Trad., P. Henry, Ver.). Albi-França: École d’Été. Recuperado de http://www. medicinaetrabalho.med.br/arquivos/Fatores\%20humanos\%20na\%20preven\%C3\%A7\%C3\%A3o\%20de\%20 acidentes.pdf9 [10 janeiro 2013].

Nicolaci-da-Costa, A. M. (2007). O campo da pesquisa qualitativa e o método de explicitação do discurso subjacente (MEDS). Psicologia: Reflexão Crítica, 20 (1), 65-72.

Penna, A. G. (1995). Introdução à psicologia política. Rio de Janeiro: Imago.

Wadsworth, B. J. (1996). Inteligência e afetividade da criança na teoria de Piaget. São Paulo: Pioneira.

Winnicott, D.W. (1983). O ambiente e os processos de maturação: estudos sobre a teoria do desenvolvimento emocional. Porto Alegre: Artmed.

Winnicott, D.W. (2000). Da pediatria à psicanálise: obras escolhidas. Rio de Janeiro: Imago.

\section{Endereço para correspondência}

mlcdomingos@oi.com.br, leandrolins_psi@hotmail.com
Recebido em: 13/07/2015

Revisado em: 08/12/2016

Aprovado em: 12/12/2016 